\title{
Heat transfer intensification in emergency cooling heat exchanger and dry cooling towers on nuclear power plant using air-water mist flow
}

\author{
Akram H. Abed ${ }^{1,2}$, Sergey E. Shcheklein ${ }^{1}$, Valery M. Pakhaluev ${ }^{1}$ \\ 1 Ural Federal University named after the First President of Russia B. N. Yeltsin, 19 Mira St., Yekaterinburg, 620002, Russia \\ 2 University of Technology, Baghdad, Iraq \\ Corresponding author: Akram H. Abed (akraaam82@yahoo.com)
}

Academic editor: Boris Balakin • Received 24 July 2019 • Accepted 30 September 2019 • Published 10 December 2019

Citation: Abed AH, Shcheklein SE, Pakhaluev VM (2019) Heat transfer intensification in emergency cooling heat exchanger and dry cooling towers on nuclear power plant using air-water mist flow. Nuclear Energy and Technology 5(4): 281-287. https://doi. org/10.3897/nucet.5.47972

\begin{abstract}
Advanced nuclear power plants are equipped with passive emergency heat removal systems (PEHRS) for removing the decay heat from reactor equipment in accidents accompanied by primary circuit leakage to the final heat absorber (ambient air). Herein, the intensity of heat dissipation to air from the outer surface of the heat exchanger achieved by buoyancy induced natural convection is extremely low, which need to a large heat exchanger surface area, apply different types of heat transfer intensification including (grooves, ribs and extended surfaces, positioning at higher altitudes, etc.). The intensity of heat removal is also strongly dependent on the ambient air temperature (disposable temperature head).

Construction of nuclear power plants in countries with high ambient temperatures (Iran, Bangladesh, Egypt, Saudi Arabia, and others) which are characterized by a high level of ambient temperature imposes additional requirements on the increase of the heat exchange surfaces.

The experimental investigation results of heat transfer intensification by a low energy ultrasonic which supply a fine liquid droplet (size $\sim 3 \mu \mathrm{m}$ ) in the cooling air are presented in the present paper. In such case, the heat transfer between the surface and cooling flow involves the following three physical effects: convection, conductive heat transfer, and evaporation of water droplets. The last two effects weakly depend on the ambient air temperature and provide an active heat removal in any situation.

The investigation was performed using a high-precision calorimeter with a controlled rate of heat supply (between 7800 and $12831 \mathrm{~W} / \mathrm{m}^{2}$ ) imitating heated surface within the range of Reynolds numbers from 2500 to 55000 and liquid (water) flow rates from 23.39 to $111.68 \mathrm{~kg} \cdot \mathrm{m}^{-2} \cdot \mathrm{h}^{-1}$.

The studies demonstrated that the presence of finely dispersed water results in a significant increase in heat transfer compared with the case of using purely air-cooling. With a fixed heat flux, the energy efficiency increases with increasing water concentration, reaching the values over $600 \mathrm{~W} \cdot \mathrm{m}^{-2} \cdot \mathrm{C}^{-1}$ at $111.68 \mathrm{~kg} \cdot \mathrm{m}^{-2} \cdot \mathrm{h}^{-1}$, which is 2.8 times higher than for air cooling. With further development of research in order to clarify the optimal areas of intensification, it is possible to use this technology to intensify heat transfer to the air in dry cooling towers of nuclear power plants and thermal power plants used in hot and extreme continental climates.
\end{abstract}

* Russian text published: Izvestiya vuzov. Yadernaya Energetika (ISSN 0204-3327), 2019, n. 3, pp. 16-27. 


\section{Keywords}

Nuclear power plants, aerosol cooling, air-water mist, water concentration, heat exchange intensification.

\section{Introduction}

Advanced nuclear power plants are equipped with passive systems for emergency decay heat removal from reactor equipment (PEHRSs) to the final heat absorber (ambient air) in case of development of accidents accompanied with primary cooling circuit leakage and for transferring heat to the final heat absorber (ambient air) (Mousavian et al. 2004; Maio Vitale et al. 2012; Zhang et al. 2012; Dmitriev et al. 2013). For nuclear power plants designed in Russia, passive safety systems were firstly used in the AES-92 Project followed by all subsequent design projects (AES-2006, VVER-1200, VVER-TOI). Design of passive safety system is based on the use of special loop transferring heat to air heat exchangers (Zvirin 1981; Andrushechko et al. 2010; Safety assessment report 2013). PEHRS in its present form consists of four independent loops incorporating heat exchange equipment with air ducts (Galiev et al. 2017). Removal of heat from outer surfaces of the heat exchanger is achieved using the processes based on the action of natural forces, such as unforced natural circulation. Driving forces of the process of natural circulation are extremely weak, which necessitates the development of equipment with expanded heat exchange surface, application of different methods for intensification of heat transfer (grooves, ribs and extended cooling surfaces, etc.), installation of draw stack with significant height for increasing the velocity of air propagation. The rate of heat removal by PEHRS, as well as heat removal in dry cooling towers influence the NPP operational performance, it can vary under the effects of different ambient factors, such as ambient air temperature, sun radiation, side wind, rain and snow (Yang et al. 2013; Fahmy and Nabih 2016; Li et al. 2018). The location of the NPPs plays an important role in the efficiency of the equipment. Construction of NPPs in such countries as Iran, Iraq, Bangladesh, Egypt, Saudi Arabia, etc. with high air temperatures (up to $55^{\circ} \mathrm{C}$ in the summer) creates additional problems for designing modules of PEHRS heat exchangers and dry cooling towers. Development of advanced more compact and efficient cooling technologies suitable for operation at high ambient air temperatures constitutes an important task. It is demonstrated in the present paper that high intensity of heat transfer with a significant reduction of dimensions and weight of heat exchange modules can be achieved using water finely dispersed in air. Application of the air-water mist cooling method is achieved by the injection of micro-size water droplets in the air cooling the heat exchange surfaces. Use of air-water mist as the working medium for dissipating heat is preferable as compared with purely air-cooling. The main distinguishing features of cooling using air-water mist as compared with single-phase air cooling can be explained as follow: absorb large quantities of thermal energy in the process of evaporation, increase of heat capacity of the cooling mixture, and increase the turbulence in the boundary layers of the air flow (Bhatti and Savery 1975; Wataru et al. 1988; Wang and Dhanasekaran 2010). The heat transfer mechanisms can include the following three important effects: convection, conductive heat transfer and evaporation of water droplets. The last two effects are weakly dependent on the external factors and ensure active heat removal within wide range of ambient temperatures. This technology can be used in the projects of upgrades of existing and development of new PEHRS, as well as dry cooling towers of nuclear and thermal power plants operated in the conditions of the hot climate. The aim of the present study was to implement an experimental investigation of the effects of air-water mist droplets on the heat transfer intensification. Experiments were conducted using a copper calorimetric sphere as the model of the heated surface at various densities of heat flux, water concentrations and velocities of airflow following the methodology represented in (Hayashi et al. 1990, 1991).

According to Dalton's law, the rate of evaporation from the surface of a body $W$ in $\mathrm{kg} /\left(\mathrm{m}^{2} \cdot \mathrm{s}\right)$ is directly proportional to the moisture deficit calculated using the temperature of the evaporating surface and inversely proportional to the atmospheric pressure (Huang et al. 2015):

$$
W=A\left(X_{T, s p h}-X_{T, i n}\right) / P,
$$

where $X_{T, s p h}$ is the elasticity of saturation taken using the temperature of the evaporating surface, $\mathrm{GPa} ; X_{T, i n}$ is the elasticity of vapor in the ambient air, $\mathrm{GPa} ; P$ is the atmospheric pressure, $\mathrm{GPa} ; A$ is the proportionality factor dependent on the air flow velocity.

It is clear from Dalton's law that the higher is the difference $X_{T, s p h}-X_{T, i n}$ the higher is the evaporation rate. If the evaporating surface is warmer than the air, then $X_{T, s p h}$ exceeds $X_{T, i n}$. In such case, evaporation continues even when air is saturated with water vapor.

\section{Experimental facility and research methodologies}

General layout of the test stand for investigation of processes of heat dissipation from the surface by air-water mist is presented in Fig. 1.

The test stand consists of the measuring section with the object under measurement (spherical element with 


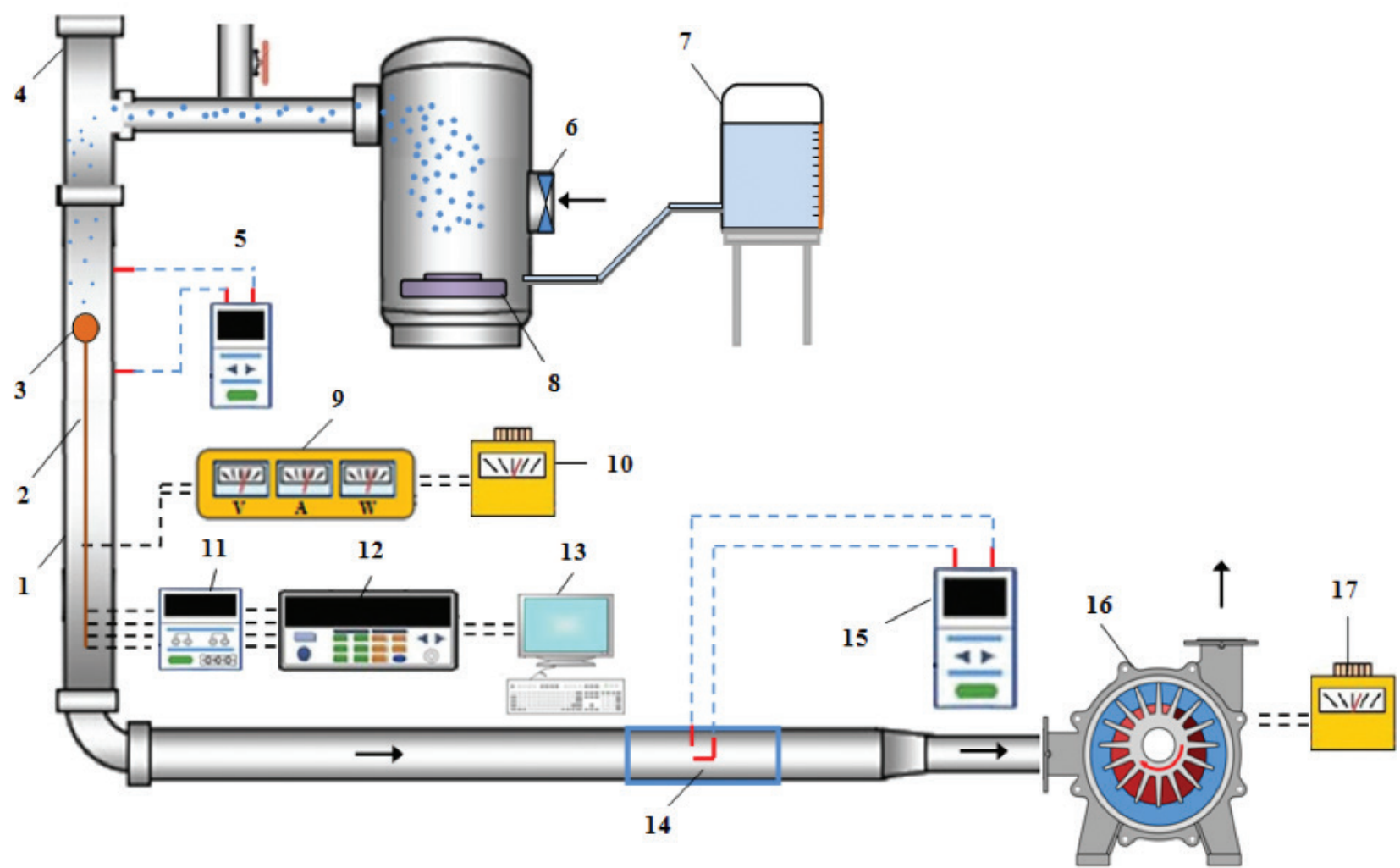

Figure 1. General layout of the experimental stand: 1 - plexiglass tube; 2 - support; 3 - copper sphere; 4 - blending chamber; 5 , 15 - differential pressure gauge; 6 - fan; 7 - tank; 8 - ultrasonic mist generator; 9 - multimeter; 10, 17 - voltage controller; 11 analogue output module; 12 - data collection module; 13 - computer; 14 - Pitot tube; 16 - air pump.

embedded heater), air supply, mist generation, phase blending and data collection subsystems (temperature, water and air flowrates, pressure, etc.).

Measurement section is the transparent channel with $50 \mathrm{~mm}$ diameter, $2 \mathrm{~mm}$ wall thickness and total length of $940 \mathrm{~mm}$. The measured object - a sphere with $34 \mathrm{~mm}$ diameter made of copper - is mounted inside the channel and is supported from the rear side with a fabric-reinforced laminate rod with $4 \mathrm{~mm}$ diameter.

Air supply subsystem incorporates electric vacuum air blowers (3000 rpm, $1000 \mathrm{~W}$ ) with air flowrate controller, compact Pitot head equipped with digital micromanometer for measuring average airflow velocity.

Spherical element is heated using alternate current electrical heater installed in the stainless steel casing with 8-mm diameter and 31-mm length. Electrical heater power is controllable for achieving the required heat flux on the surface of the sphere using RNO-250-1000 autotransformer and is measured using APPA $109 \mathrm{~N}$ digital multimeter with $\pm 0.06 \%$ precision.

Special high-temperature heat-conducting paste is used for reducing thermal resistance between the metal of the sphere and the electrical heater.

Schematic layout of the spherical element with heater and thermocouples is shown in Fig. 2. Five calibrated chromium-nickel thermocouples are applied for measuring temperature of the spherical surface as follows: two thermocouples are mounted inside the copper sphere (po- sitions 1 and 2 in Fig. 2), one thermocouple is installed in the inlet flow zone and two thermocouples are positioned at the outlet of the flow after flowing around the sphere. Thermocouples 1 and 2 are caulked in the holes with 1-mm diameter drilled on the surface of the sphere and are thoroughly polished.

All thermocouples are connected to the data collection system consisting of the analogue signal input module of OWEN MV110-8A type, MSD200 data registration device and personal computer.

Air-water mist is generated as the result of injection of micro-size water droplets in the airflow inside the blending chamber. Ultrasonic mist generator with piezoelectric transducers and generator operated at $1.7-\mathrm{MHz}$ frequency (Kudo et al. 2017) is applied as the mist generation subsystem. This type of mist generator was selected due to the low energy consumption and noiseless operation in contrast with other generators of mist and vapors. Dimensions of the droplets were calculated using Lang formula (Lang 1962) for ultrasonic spraying of the liquid and were found to be equal to $2.73 \mu \mathrm{m}$.

Mass flow rate of the sprayed water was determined according to the change of water mass in the tank of the mist generation subsystem per unit time. Mixture of finely dispersed water with controlled amount of air is formed in the blending chamber. Application of the process of air humidification under discussion here allows obtaining air-water mist with low mass humidity 


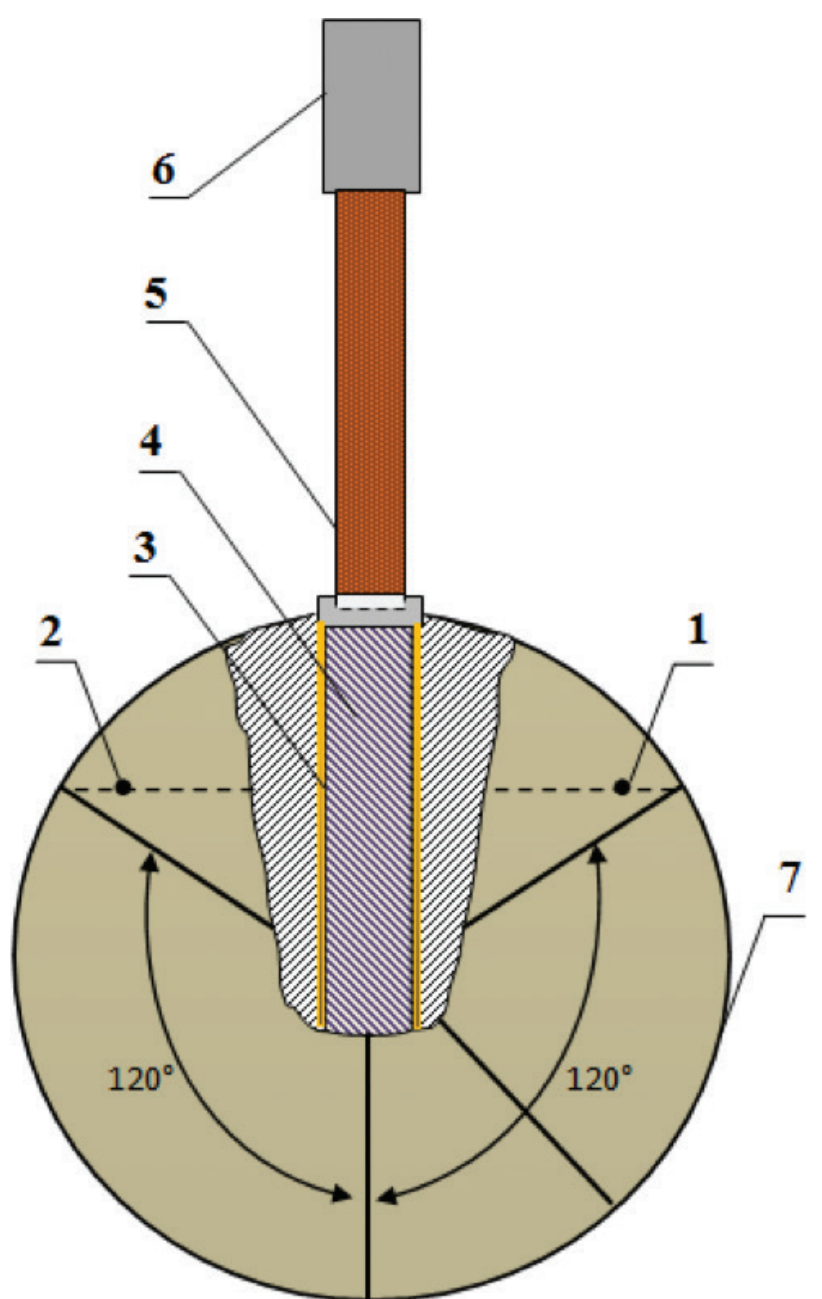

Figure 2. Layout of the spherical element: 1,2 - thermocouples; 3 - thermal paste; 4 - electrical heater; 5 - fiber-reinforced laminate rod; 6 - support; 7 - copper sphere.

varying in the course of experiments within the range from 0.1 to $6 \%$.

The precision of measurements of calorimeter temperature amounted to $4 \%$. Uncertainties of measurements of air and water flowrates, heater power and geometrical characteristics ranged from two to $3 \%$. Multiple repetitions of measurements at the preset regimes produced statistical dispersion of results within 5\%.

The following dimensionless criteria were used in the processing of experimental results:

- Reynolds number $\operatorname{Re}=U \times D / \mathrm{n}$, where $U$ is the velocity of air flow in the channel, $\mathrm{m} / \mathrm{s} ; D$ is the internal diameter of the channel, $\mathrm{m}$; $\mathrm{n}$ is the air kinematic viscosity, $\mathrm{m}^{2} / \mathrm{s}$;

- Nusselt number $\mathrm{Nu}=\mathrm{a} \times d / 1$, where $\mathrm{a}$ is the heat transfer coefficient, $\mathrm{W} /\left(\mathrm{m}^{2} \times \mathrm{K}\right) ; d$ is the diameter of the sphere, $\mathrm{m} ; 1$ is the thermal conductivity of air, $\mathrm{W} /(\mathrm{m} \times \mathrm{K})$.

Uncertainties of calculation of Nusselt and Reynolds numbers amount to less than $10 \%$, which allows reliable detection of the effect of heat transfer intensification.

\section{Experimental data processing}

Equation for the sum of convection $Q_{\text {conv }}$, conductive $Q_{\text {cond. }}$ components of heat transfer and evaporation of water droplets $Q_{\mathrm{ev}}$ on the heated surface (Allais and Alvarez 2001, Allais et al. 2006) was used in the analysis of interaction between the heated surface and the flow of air-water mist:

$$
\begin{aligned}
& Q=Q_{\text {conv. }}+Q_{\text {cond. }}+Q_{\text {ev. }}, \\
& Q_{\text {conv. }}=\mathrm{a} F_{\text {sph }}\left(T_{\text {av.sph }}-T_{\text {in }}\right), \\
& Q_{\text {cond. }}=M_{d} C_{p, \mathrm{w}}\left(T_{\text {av.sph }}-T_{\text {in }}\right), \\
& Q_{\text {ev. }}=\mathrm{a} F_{\text {wet. }}\left(X_{T, \text { sph }}-X_{T, \text { in }}\right) r / C_{p, \text { w }},
\end{aligned}
$$

where a is the heat transfer coefficient; $F_{\text {sph }}$ is the surface of the sphere; $T_{\mathrm{avsph}}$ is the average temperature of the surface of the sphere; $T_{\text {in }}$ is the inlet temperature of the mist; $M_{d}$ is the water mass flowrate; $C_{p, \mathrm{w}}$ is the water heat capacity; $F_{\text {wet }}$ is the area of the wetted surface of the sphere; $X_{T, \mathrm{sph}}$ is the concentration of moisture for the temperature of the sphere; $X_{T, \text { in }}$ is the concentration of moisture at the temperature at the mist inlet in the channel.

It is assumed that part of water precipitates on the surface in the process of the mist flowing around the heated sphere. Part of water droplets evaporates, while some of them remain scattered in the main airflow. Experiments were conducted with pure dry air and with air-water mist within the range of water flow densities $(j=23.39,46.79$, 88.31 , and $\left.111.68 \mathrm{~kg} \cdot \mathrm{m}^{-2} \cdot \mathrm{hr}^{-1}\right)$. Range of Reynolds numbers is $2500-55000$.

\section{Results and discussion}

\subsection{Surface temperature}

Temperature of the surface is an important factor exercising significant influence on the process of heat transfer to air-water mist. When surface temperature is very high, finely dispersed water can completely evaporate before it attains the complete heated surface. On the other hand, wetting of the heated surface and formation of liquid film may take place at low surface temperature. Several values of heat flux were examined for investigating the effects of surface temperature on the heat transfer coefficient. Average temperature of the surface is shown in Fig. 3 for different heat fluxes, Reynolds numbers and liquid phase (water) flow density.

Surface temperature decreases with increasing Reynolds number in the case of single-phase air flow. Because of evaporation of water, surface temperature decreases in the air-water mist with increasing water flow density at constant heat flux. Surface temperature decreases by $4,17,37$ and $47 \%$ as compared to air because of the increase of water flow density. It was found using the methods of direct observation and photography and video filming that the heated surface is covered with thin water film at high density of liquid 

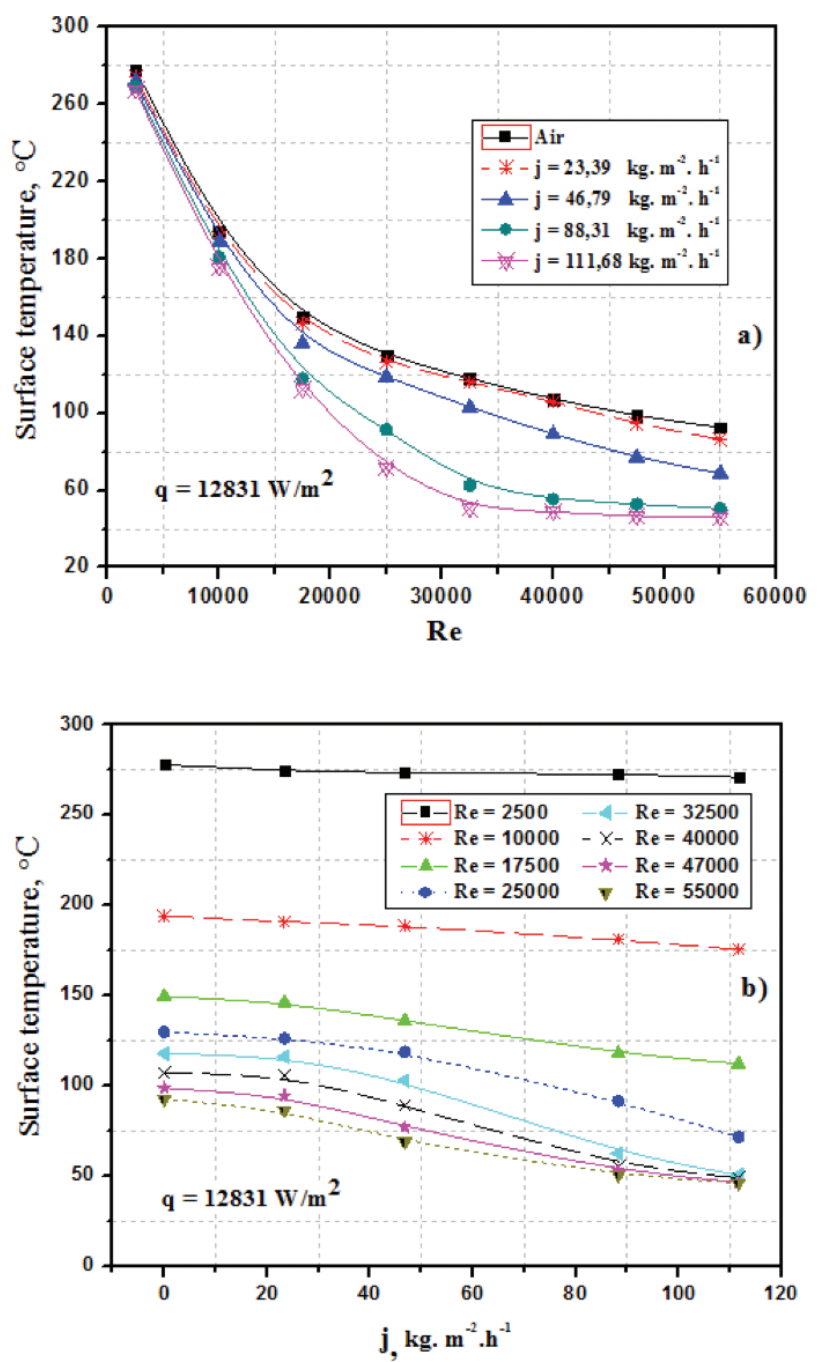

Figure 3. Evolution of surface temperature depending on the Reynolds number (a) and on the density of liquid phase (water) flow in the mist (b).

flow and the values of $\operatorname{Re}>17500$. At the same time heated surface remains dry at $\operatorname{Re}<17500$ for all values of heat flux.

\subsection{Heat transfer coefficient}

Variation of average heat transfer coefficient in the form of dependence $\mathrm{Nu}=f(\mathrm{Re})$ is shown in Fig. 4 for two values of heat flux at different values of water flow density in the mist. For $q=7800 \mathrm{~W} / \mathrm{m}^{2}$ and $10155 \mathrm{~W} / \mathrm{m}^{2}$ average Nusselt number monotonously increases with increasing water flow density within the whole range of Reynolds numbers. It is important to note that maximum increase is observed at high concentration of water phase and low surface temperature of the sphere.

It can be noted that average Nusselt number significantly increases with increase of Reynolds number for any water flow density. Value of $\mathrm{Nu}$ increases in single-phase flow from 66 to 240 within the range of Re from 2500 to 55000 at constant heat flux $\left(q=10155 \mathrm{~W} / \mathrm{m}^{2}\right)$. Within the investigated range of Reynolds numbers Nusselt numbers
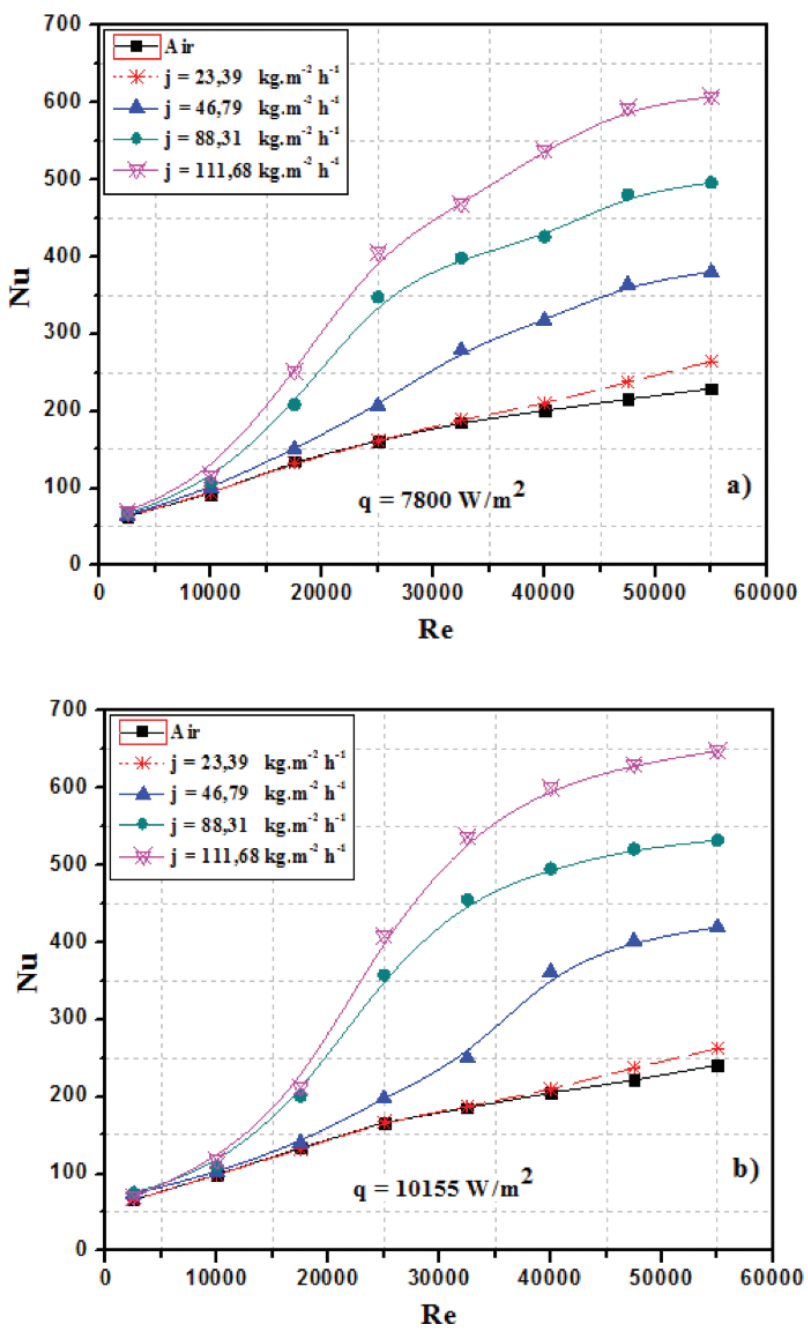

Figure 4. Dependence of average Nusselt number on the Reynolds number for heat fluxes equal to $7800 \mathrm{~W} / \mathrm{m}^{2}$ (a) and10155 $\mathrm{W} / \mathrm{m}^{2}$ (б) for different values of water flow density in the mist.

for air-water mist are by 1, 19.7, 90.2 and $134 \%$ higher than in the air flow for water flow density $j=23.39,46.79$, 88.31 and $111.68 \mathrm{~kg} \cdot \mathrm{m}^{-2} \cdot \mathrm{hr}^{-1}$, respectively.

High Reynolds numbers correspond to high flow velocity and, consequently, in air-water mist more and more water precipitates from the mist on the surface of the sphere and absorbs significant energy in the process of evaporation.

Finely dispersed water can create filmy layer and enhance the process of heat transfer by increasing contact surface with the main flow. Reduction of Nusselt number due to evaporation of water from the mist without direct wetting of the heated surface occurs with increasing surface temperature $(\operatorname{Re}<17500)$.

\section{3. Generalized dependence of the heat transfer in- tensification coefficient}

Relative change of heat transfer to the mist depending on the air-cooling is presented in Fig. 5.

Within the range of small water flow density ( $j$ varying from 23.39 to $46.79 \mathrm{~kg} \cdot \mathrm{m}^{-2} \cdot \mathrm{hr}^{-1}$ ) with $q=$ const. the factor 


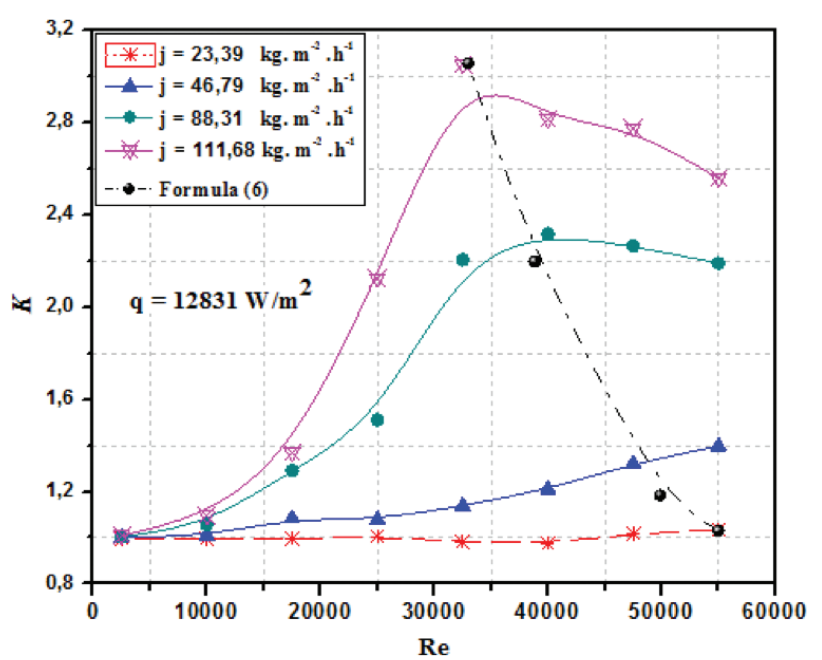

Figure 5. Variation of the heat transfer intensification factor depending on the Reynolds number for different water flow densities in the mist.

characterizing intensification of heat transfer undergoes contradictory variation with increasing Re due to the relative reduction of water content in the air-water mist.

Within the whole range of variation of values of moisture concentration there exists the area of optimal intensification of heat transfer determined by the correlation between the mechanisms of evaporation and precipitation of moisture on the surface of the sphere. Mass concentration of moisture in the mist within this optimal zone falls within the range from 0.3 to $0.6 \%$. Dependence of optimal values of the heat transfer intensification factor on the air flowrates (Re number) and on mass moisture concentration $x$ is represented for $d / D=$ const by the following equation:

$$
K^{\max }=1+\mathrm{Re}^{1.18} \times x^{2.2} .
$$

The above equation is valid within the range of Reynolds numbers from 32000 to 60000 and water flow densities from zero to $111.68 \mathrm{~kg} \cdot \mathrm{m}^{-2} \cdot \mathrm{hr}^{-1}$.

Stabilization and smooth reduction of the degree of intensification is observed for $j>80 \mathrm{~kg} \cdot \mathrm{m}^{-2} \cdot \mathrm{hr}^{-1}$ and high flow velocities of air-water mist after passing through the optimal value. For $j<20 \mathrm{~kg} \cdot \mathrm{m}^{-2} \cdot \mathrm{hr}^{-1}$ intensification of

\section{References}

- Allais I, Alvarez G (2001) Analysis of heat transfer during mist chilling of a packed bed of spheres simulating foodstuffs. Journal of Food Engineering 49(1): 37-47. https://doi.org/10.1016/S02608774(00)00182-5

- Allais I, Alvarez G, Flick D (2006) Modeling cooling kinetics of a stack of spheres during mist chilling. Journal of Food Engineering 72(2): 197-209. https://doi.org/10.1016/j.jfoodeng.2004.11.010

- Andrushechko SA, Afrov AM, Vasilyev BYu, Generalov VN, Kosourov KB, Semchenkov YuM, Ukraintsev VF (2010) NPP with heat transfer is practically non-existent within the whole range of investigated velocities of the mist flow and heat flux values.

\section{Conclusion}

Test facility and methodology for investigation of heat transfer characteristics were developed for the case when the heat transfer surfaces of the model of PEHRS heat exchange element are cooled down by air-water mist. Investigation of heat transfer was performed within wide range of heat flux values, Reynolds numbers and concentrations of water droplets for the case of cooling of object with air-water mist. The following conclusions can be drawn based on the experimental results obtained.

Use of air-water mist is an efficient method for cooling heat exchange surfaces. Temperature of the surface decreases by $4,17,37$ and $47 \%$ as compared with cooling by air flow for water flow densities $j=23.39,46.79,88.31$ and $111.68 \mathrm{~kg} \cdot \mathrm{m}^{-2} \cdot \mathrm{hr}^{-1}$, respectively.

Average Nusselt number significantly increases with increased Reynolds number for all values of heat flux and water flow densities. When finely dispersed water is used, the average Nusselt number is found to be 11, 19.7, 90.2 and $134 \%$ higher than for the case of cooling with air flow for water flow densities $j=23.39,46.79,88.31,111.68$ $\mathrm{kg} \cdot \mathrm{m}^{-2} \cdot \mathrm{hr}^{-1}$, respectively. Average Nusselt number increases with increased heat flux for fixed values of water flow density and Reynolds numbers.

The value of the factor characterizing heat transfer intensification in the case of cooling with air-water mist flow is significantly higher (up to $300 \%$ ) than for the case of air cooling and has area of optimal moisture concentration for each value of water flow velocity.

\section{Acknowledgements}

The present study was implemented under the financial support in pursuance with Resolution No. 211 of the Government of the Russian Federation under Contract No. 02.A03.21.0006.
VVER-1000 type Reactor. From Physical Basics of Operation to Design Evolution. Moscow. Logos Publ., 604 pp. [in Russian]

- Bhatti M, Savery C (1975) Augmentation of Heat Transfer in a Laminar External Gas Boundary Layer by the Vaporization of Suspended Droplets. Journal of Heat Transfer 97(2): 1-179. https://doi. org/10.1115/1.3450338

- Dmitriev SM, Morozov AV, Remizov OV (2013) Passive Core Cooling Systems for Various Types of Nuclear Reactors. N. Novgorod, NGTU Publ., 77 pp. [in Russian] 
- Fahmy M, Nabih H (2016) Impact of ambient air temperature and heat load variation on the performance of air-cooled heat exchangers in propane cycles in LNG plants. - Analytical approach. Energy Convers. Manage 121: 22-35. https://doi.org/10.1016/j.enconman.2016.05.013

- Galiev K, Yaurov S, Goncharov Y, Volnov A (2017) Experience of commissioning of the V-392M reactor plant passive heat removal system. Nuclear Energy and Technology 3(4): 291-296. https://doi. org/10.1016/j.nucet.2017.11.003

- Hayashi Y, Takimoto A, Matsuda O (1991) Heat transfer from tubes in mist flows. Experimental Heat Transfer 4(4): 291-308. https://doi. org/10.1080/08916159108946422

- Hayashi Y, Takimoto A, Matsuda O, Kitagawa T (1990) Study on Mist Cooling for Heat Exchanger: Development of High-Performance MistCooled Heat Transfer Tubes. JSME International Journal. Ser. 2, Fluids Engineering, Heat Transfer, Power, Combustion, Thermophysical Properties 33(2): 333-339. https://doi.org/10.1299/jsmeb1988.33.2_333

- Huang XG, Yang YH, Hu P (2015) Experimental study of falling film evaporation in large scale rectangular channel. Annals of Nuclear Energy 76: 237-242. https://doi.org/10.1016/j.anucene.2014.09.053

- Kudo T, Sekiguchi K, Sankoda K, Namiki N, Nii S (2017) Effect of ultrasonic frequency on size distributions of nanosized mist generated by ultrasonic atomization. Ultrasonics Sonochemistry 37: 16-22. https://doi.org/10.1016/j.ultsonch.2016.12.019

- Lang RJ (1962) Ultrasonic atomization of liquid. Journal of the Acoustical Society of America 34: 6-8. https://doi.org/10.1121/1.1909020

- Li X, Gurgenci H, Guan Z, Sun Y (2018) Experimental study of cold inflow effect on a small natural draft dry cooling tower. Applied Thermal Engineering 128: 762-771. https://doi.org/10.1016/j. applthermaleng.2017.09.071
- Maio Vitale Di, Naviglio D, Giannetti A, Manni F (2012) An innovative pool with a passive heat removal system. Energy 45(1): 296-303. https://doi.org/10.1016/j.energy.2012.03.053

- Mousavian S, D’Auria F, Salehi M (2004) Analysis of natural circulation phenomena in VVER-1000. Nuclear Engineering and Design 229(1): 25-46. https://doi.org/10.1016/j.nucengdes.2003.11.012

- Safety assessment report (2013) Novovoronezh NPP-2 Power Unit No. 1. Chapter 12. Safety systems. Moscow. JSC Atomenergoproect Publ., 240 pp. [in Russian]

- Wang T, Dhanasekaran T (2010) Calibration of a Computational Model to Predict Mist/Steam Impinging Jets Cooling With an Application to Gas Turbine Blades. Journal of Heat Transfer 132(12): 122201. https://doi.org/10.1115/1.4002394

- Wataru N, Heikichi K, Shigeki H (1988) Heat transfer from tube banks to air/water mist flow. International Journal of Heat and Mass Transfer 31(2): 449-460. https://doi.org/10.1016/00179310(88)90027-0

- Yang LJ, Wu XP, Du XZ, Yang YP (2013) Dimensional characteristics of wind effects on the performance of indirect dry cooling system with vertically arranged heat exchanger bundles. International Journal of Heat and Mass Transfer 67: 853-866. https://doi. org/10.1016/j.ijheatmasstransfer.2013.08.085

- Zhang Y, Qiu S, Su G, Tian W (2012) Design and transient analyses of emergency passive residual heat removal system of CPR1000. Nuclear Engineering and Design 242: 247-256. https://doi. org/10.1016/j.nucengdes.2011.09.036

- Zvirin Yu (1981) A review of natural circulation loops in PWR and other systems. Nucl. Eng. Design 67: 203-225. https://doi. org/10.1016/0029-5493(82)90142-X 